\title{
Fabrication of Poly (Acrylonitrile-Co-Methyl Methacrylate) Nanofibers Containing Boron via Electrospinning Method: A Study on Size Distribution, Thermal, Crystalline, and Mechanical Strength Properties
}

\author{
Meisam Sadeghi ${ }^{1}$, Zahra Moghimifar ${ }^{2}$, P. Senthil Kumar ${ }^{3, * \mathbb{D} \text {, Hamedreza Javadian }}{ }^{4, *}$ and Majid Farsadrooh $^{5}$ \\ 1 Faculty of Chemical Engineering, Nanotechnology Research Institute, Babol Noushirvani University of \\ Technology, Babol 47148-71167, Iran; m-sadeghi@nlai.ir \\ 2 Chemistry and Chemical Engineering Research Center of Iran (CCERCI), Tehran 14335-186, Iran; \\ 97m_z.moghimifar@ccerci.ac.ir \\ 3 Department of Chemical Engineering, Sri Sivasubramaniya Nadar College of Engineering, \\ Kalavakkam 600020, India \\ 4 Department of Chemical Engineering, ETSEIB, Universitat Politècnica de Catalunya, 08028 Barcelona, Spain \\ 5 Renewable Energies Research Laboratory, Department of Chemistry, Faculty of Sciences, University of Sistan \\ and Baluchestan, Zahedan 98167-45785, Iran; majidfarsad@usb.ac.ir \\ * Correspondence: senthilkumarp@ssn.edu.in (P.S.K.); hamedreza.javadian@upc.edu (H.J.)
}

Citation: Sadeghi, M.; Moghimifar, Z.; Kumar, P.S.; Javadian, H.; Farsadrooh, M. Fabrication of Poly (Acrylonitrile-Co-Methyl

Methacrylate) Nanofibers Containing Boron via Electrospinning Method: A Study on Size Distribution, Thermal, Crystalline, and Mechanical Strength Properties. Sustainability 2021, 13 , 4342. https://doi.org/10.3390/ su13084342

Academic Editor: Abdel El-kharbach

Received: 17 February 2021

Accepted: 7 April 2021

Published: 14 April 2021

Publisher's Note: MDPI stays neutra with regard to jurisdictional claims in published maps and institutional affiliations.

Copyright: (C) 2021 by the authors Licensee MDPI, Basel, Switzerland. This article is an open access article distributed under the terms and conditions of the Creative Commons Attribution (CC BY) license (https:// creativecommons.org/licenses/by/ $4.0 /)$.

\begin{abstract}
Electrospun polymeric nanofibers have attracted great attention in filtration systems and protective clothes. One of them is polyacrylonitrile (PAN) nanofibers, which are a suitable choice for the fabrication of protective clothes in the defense industry, due to their good fiber formation and easy optimization with chemical reagents. They do not possess adequate properties for protection against chemical, biological, and radiological agents. In this research, poly (acrylonitrile-co-methyl methacrylate) (PANMM) nanofibers and PANMM nanofibers containing ${ }^{10} \mathrm{~B}$ were fabricated via the electrospinning method. The study of the morphology of nanofibers, using scanning electron microscopy (SEM), revealed that smooth and knotted fibers with an average diameter of $259 \pm 64 \mathrm{~nm}$ were obtained, using $12 \%(w / v)$ of PANMM in the solution as the optimal concentration for the electrospinning process. This sample was doped with boron $(10 \%, 30 \%$, and $50 \%(w / w))$ to fabricate the samples of PANMM + boric acid (BA) nanofibers. The results demonstrated an increasing trend in the diameter of the nanofibers with an increase in BA up to $50 \%$. At this concentration, smooth fibers were formed with lower knots. Furthermore, the presence of B-O and O-H groups was observed using Fourier transform infrared (FTIR) spectroscopy. To study the tensile properties, the nanofibrous web was tested, and the results showed that introducing ${ }^{10} \mathrm{~B}$ to PANMM nanofiber structures reduced the strength of the nanofibers. Thermal gravimetric analysis (TGA) showed that BA-modified PANMM nanofibers had lower thermal degradability, as compared with pure PANMM.
\end{abstract}

Keywords: electrospinning; polyacrylonitrile nanofiber; boron; characterization

\section{Introduction}

Electrospinning is a novel and efficient method, which uses an electric field to produce fine polymeric fibers with a significant reduction in the diameter of the fibers to the range of nanometers [1]. It has several useful applications, such as bio/medical, membrane, filtration, drug delivery, composite materials, etc. [2-10].

Carbon fiber reinforced polymers are an important kind of versatile reinforcement structure for polymeric fibers [11]. Polyacrylonitrile (PAN) is one of the main precursors for manufacturing carbon fibers because of its high quality and the fact that it is high-tech material [12]. PAN-based carbon fibers (CFs) are greatly used in aerospace and defense industries, due to their excellent mechanical properties, such as low density (1.7-2.2 g cm-3), 
high tensile strength (3-7 GPa), and high Young's modulus value (200-700 GPa) [13,14]. PAN fibers are important synthetic fibers in the textile industry; they are spun from acrylonitrile copolymers containing more than $85 \%$ of PAN with outstanding properties, such as excellent warmth retention, good elasticity, etc. [5,15]. Furthermore, they are known as one of the most combustible synthetic fibers, which produce heavy smoke and toxic hydrogen cyanide when on fire. Consequently, the developments of PAN fibers' applications, particularly imparting PAN fibers with flame retardant properties, have become significantly important [16].

The production of flame-retardant PAN fibers can be carried out through surface modification, blending, and copolymerization methods [17]. In the latter method, flameretardant elements are introduced to acrylonitrile macromolecular chains through a covalent bond, resulting in durable flame-retardant performance. The main drawback of this method is that the cost of production significantly increases. In addition, acrylonitrile has high molecular weight due to the relatively high molecular weight of the copolymers [18]. Surface modification is used as a simple and cost-effective method to introduce flame retardancy. In this method, there are disadvantages, such as the yellow or brown color of fibers, that limit its broad range applications and poor mechanical properties [19].

Boron and its compounds are applied extensively in the nuclear industry, such as in control/shut off rods in nuclear reactors, sensors for neutron counting, shapes for neutron shielding, etc., due to their high neutron absorption cross section. The neutron absorption of enriched ${ }^{10} \mathrm{~B}$ is sufficiently high at 1 barn for $1 \mathrm{MeV}$ neutron energy. Boric acid (BA) and boron carbide as neutron absorbers in the nuclear industry are two principal compounds of boron materials. BA is used in the moderator/coolant of research reactors and developed due to its high absorption cross sections [20]. Several studies have shown the protective characteristics of ${ }^{10} \mathrm{~B}$ against ultraviolet (UV) radiation; therefore, investigations have been carried out for the modification of the textiles' structure in order to increase their UV protection factor [16]. Commonly, protection provided by normal clothing is insufficient to protect skin from UV radiation damage. Thus, attempts on improving UV protection have increased, and several methods have been proposed and compared for doping ${ }^{10} \mathrm{~B}$ onto $\mathrm{CFs}$, such as the (1) dissolution-reprecipitation of carbon for the formation-decomposition of carbides and/or the (2) oxidative stabilization method, which makes a tunable balance between the reaction rates of cyclization and oxidation during stabilization [21]. In these two methods, the heterogeneous nature of boron distribution inside the CFs has demonstrated difficulty in the diffusion of BA and placing boron on the surface. The most promising methods of CF production with $B$ precursors have been reported in the form of immersing fibers in solutions containing boron, such as boron carbide $\left(\mathrm{B}_{4} \mathrm{C}\right)$, boron trioxide $\left(\mathrm{B}_{2} \mathrm{O}_{3}\right)$, or $\mathrm{BA}\left(\mathrm{H}_{3} \mathrm{BO}_{3}\right)[18,20]$. On the other hand, boron compounds, such as $\mathrm{BA}$, are toxic to all species at a high dosage, but they are not mutagenic or carcinogenic. However, the toxicity mechanisms of boron remain unclear [22]. The major chronic toxicities are related to growth and reproduction. Due to the exposure of industries and consumers to boron, awareness of its toxicity is essential [23].

To overcome the problems mentioned above, researchers have carried out the modification of PAN fibers [24]. According to the results, BA could also be doped to the fibers, before drying, in the spinning process. Grassie et al. also mentioned that BA had an inhibitory role in the reaction [25]. Considering the possible ways for industrialization, immersion determined as an appropriate and easy method is performed by immersing fibers in a BA solution, using existing equipment without adding an excess process or a new machine for higher production [17]. According to the surface structures, and properties of the pure PAN fibers' structure, it can also be concluded that BA could be cross-linked to PAN fibers [26]. More results demonstrated that the content of boron (B) in polymer fibers is dependent on polymer solution concentration [17,27].

In this paper, pure poly (acrylonitrile-co-methyl methacrylate) (PANMM)and PANMM nanofibers containing BA were fabricated. The effect of PANMM and BA concentrations on the diameter of the fibers was investigated by SEM. The effects of doping BA on the 
chemical structure, thermal, crystalline, and mechanical properties of the nanofibers were investigated.

\section{Materials and Methods}

\subsection{Materials}

PAN was supplied by Polyacryl Iran Company (IRI), and then PANMM (94 wt $\%$ acrylonitrile and $6 \mathrm{wt} \%$ methyl acrylate), with the average molecular weight of around 1.7 million $\mathrm{g} /$ mole was synthesized using emulsion copolymerization at a low temperature in a closed reactor. Dimethylformamide (DMF) as a solvent and BA were supplied from Merck (GER).

\subsection{Polymer Solution Preparation}

The PANMM solutions were prepared at the concentrations of $5 \%, 12 \%$, and $20 \%$ $(w / v)$ by the PANMM nanofibers' dissolution in DMF, as a solvent. All PANMM solutions were mixed for $24 \mathrm{~h}$ on a magnetic stirrer until a homogeneous distribution was obtained. In the next step, BA was used for the electrospinning process in order to create nanofibers containing boron. For this purpose, three different polymer solutions were selected for the electrospinning process, and the samples were prepared with boron doping equal to $10 \%$, $30 \%$, and $50 \%(w / w)$ of the PANMM nanofibers. This means that the surface of the PANMM fibers is coated with $0.25,0.75$, and $1.25 \mathrm{wt} \%$ of boron. Thus, BA can be introduced onto the PANMM fibers' surface to improve the homogeneity of the structure of the PANMM fibers during the thermal treatment. First, BA was dissolved in DMF, and then the PANMM nanofibers were added to this solution. The dissolution process was performed using a magnetic stirrer for $24 \mathrm{~h}$, in combination with an ultrasonic mixing method for $6 \mathrm{~min}$, to obtain a clear solution. After dissolution, electrospinning of the solutions was performed. BA could inhibit the cyclization process, which can then occur at a higher temperature. It should be noted that electrospinning was performed at room temperature. This was intended to test the effect of the concentration of PANMM nanofibers and BA on the fibers' diameter after electrospinning. The solutions' concentrations and the electrospinning process parameters are presented in Table 1.

Table 1. Different concentrations of the prepared solutions and the parameters of the electrospinning processes.

\begin{tabular}{ccccc}
\hline Sample Code & PANMM Concentration (\%) & BA Concentration (\%) & Magnetic Stirrer (h) & Ultrasonic (min) \\
\hline S1 & $5 \%(w / v)$ & - & 24 & - \\
S2 & $12 \%(w / v)$ & - & 24 & - \\
S3 & $20 \%(w / v)$ & $10 \%(w / w)$ & 24 & - \\
S4 & $12 \%(w / v)$ & $30 \%(w / w)$ & 24 & 6 \\
S5 & $12 \%(w / v)$ & $50 \%(w / w)$ & 24 & 6 \\
S6 & $12 \%(w / v)$ & & 24 \\
\hline
\end{tabular}

\subsection{Electrospinning}

After obtaining a clear solution of the polymer, electrospinning was performed under the conditions as follows: the voltage of around $14 \mathrm{kV}, 15 \mathrm{~cm}$ distance from the needle tip to the collector plate, and the polymer feed rate of $1 \mathrm{~mL} / \mathrm{h}$ fitted with a steel needle of $337 \mu \mathrm{m}$ inner diameter. The fiber samples were electrospun, and the nanofibers were collected on aluminum foil and stored in a desiccator to investigate their properties.

\subsection{Thermal Stabilization of PANMM Fibers}

The samples of the pure PANMM were heated in an oven at $200^{\circ} \mathrm{C}$ for $1 \mathrm{~h}$ (from room temperature to $200{ }^{\circ} \mathrm{C}$ with the rate of $3{ }^{\circ} \mathrm{C} / \mathrm{min}$ ). The process was carried out in a pure inner air flow flux. 


\subsection{Characterization}

SEM images are often used to determine the diameter of fibers. Therefore, PANMM fibers were coated with gold for $120 \mathrm{~s}$ under a flow of $10 \mathrm{~mA}$, and then the fibers were observed at a voltage of $20 \mathrm{kV}$. By examining the SEM images of the samples obtained from the electrospinning of polymer solutions, the best concentration for producing fibers from PANMM solutions in DMF was obtained. A dynamic light scattering (DLS) technique (Zetasizer, Malvern, UK) was used to measure the average particle size of the prepared nanocomplexes. The samples were diluted with distilled water (the $\mathrm{pH}$ of the distilled water was adjusted according to the $\mathrm{pH}$ of the samples), and the average volumetric diameter was applied for the determination of the average particle size. X-ray diffraction (XRD, GBC MMA instrument) in the range of $2 \theta=10-70^{\circ}$ was applied for the characterization of the crystallinity of the materials. In order to study the thermal changes of nanofibers before and after the introduction of BA, TGA was used to plot the changes in the samples weight against temperature. The samples were studied by a TAQ50 instrument and heated with the rate of $10^{\circ} \mathrm{C} / \mathrm{min}$ under argon gas from $25^{\circ} \mathrm{C}$ to $840{ }^{\circ} \mathrm{C}$. In order to measure the mechanical properties, samples with dimensions of $50 \times 10 \mathrm{~mm}^{2}$ and a thickness of $0.69 \mathrm{~nm}$ were prepared. It should be mentioned that the thickness of the fibers increases obviously by increasing boron content. Then, the mechanical properties were measured using the Instron instrument, using the weight of $10 \mathrm{~N}$ at a speed of $10 \mathrm{~mm} / \mathrm{min}$. The number of replications for each experiment was 5 samples, and the averages of the results were reported as strength and elongation of the sample.

\section{Results and Discussion}

\subsection{Investigation of the SEM of the Nanofibers}

As shown in Figure 1a, at the concentration of $5 \%(w / v)$, due to the low viscosity of the polymer solution, the fibers are not formed, and the polymer particles are spread on the collector. This phenomenon can be explained by the fact that the polymer chains are not able to accumulate and form a fibrous structure, due to the low concentration of the polymer solution. As a result, the spherical particles of the polymer are charged, accelerated, and thrown toward the collector [28].

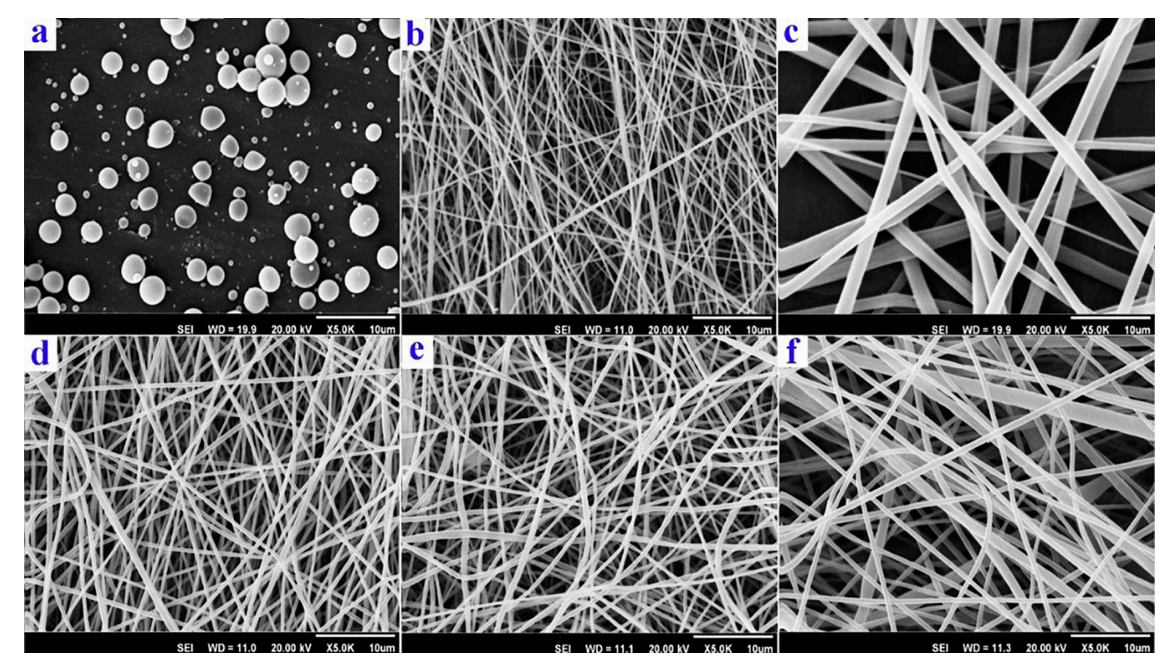

Figure 1. SEM images of the samples: (a) S1, (b) S2, (c) S3, (d) S4, (e) S5, and (f) S6.

As illustrated in Figure 1b, by increasing the concentration of the polymer solution to $12 \%$ $(w / v)$, a desired electrospinning condition is obtained, and smooth and knotted fibers with an average diameter of $259 \pm 64 \mathrm{~nm}$ are also obtained (Figure 2a). By increasing the concentration of the solution to $20 \%(w / v)$, it is observed that the diameter of fibers increases significantly (Figure 1c), and the average diameter of the fibers reaches $1400 \pm 482 \mathrm{~nm}$ (Figure 2b). To justify this, it can be said that by increasing the concentration of the polymer solution, the viscosity of the solution increases and the polymer projectile in the electric field between two electrodes 
undergoes fewer rotations and bends; consequently, the polymer is less stretched, and thus, the diameter of the fibers increases [29]. Figure 3 shows an average diameter of the unmodified nanofibers at different concentrations of PANMM.
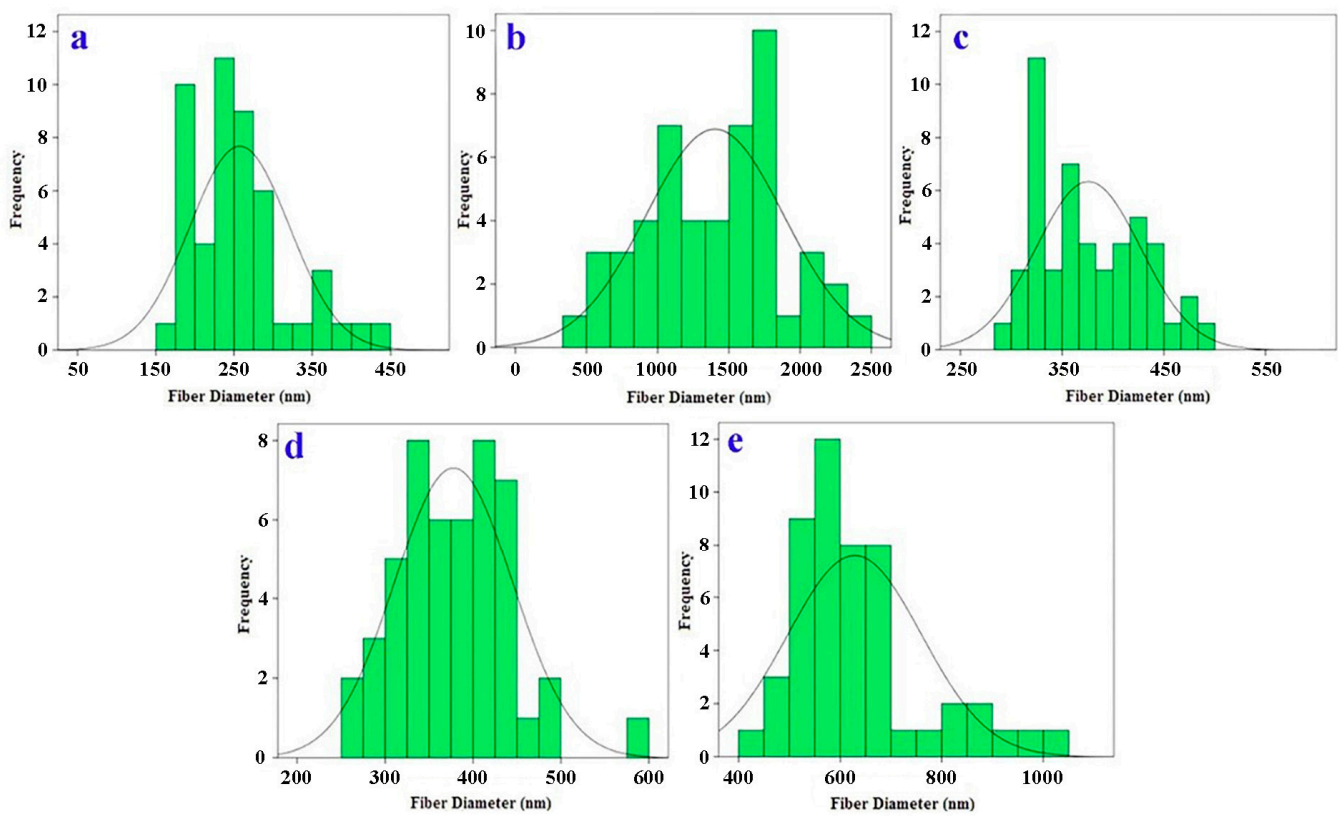

Figure 2. Dynamic light scattering (DLS) diagram of the samples: (a) S2, (b) S3, (c) S4, (d) S5, and (e) S6.

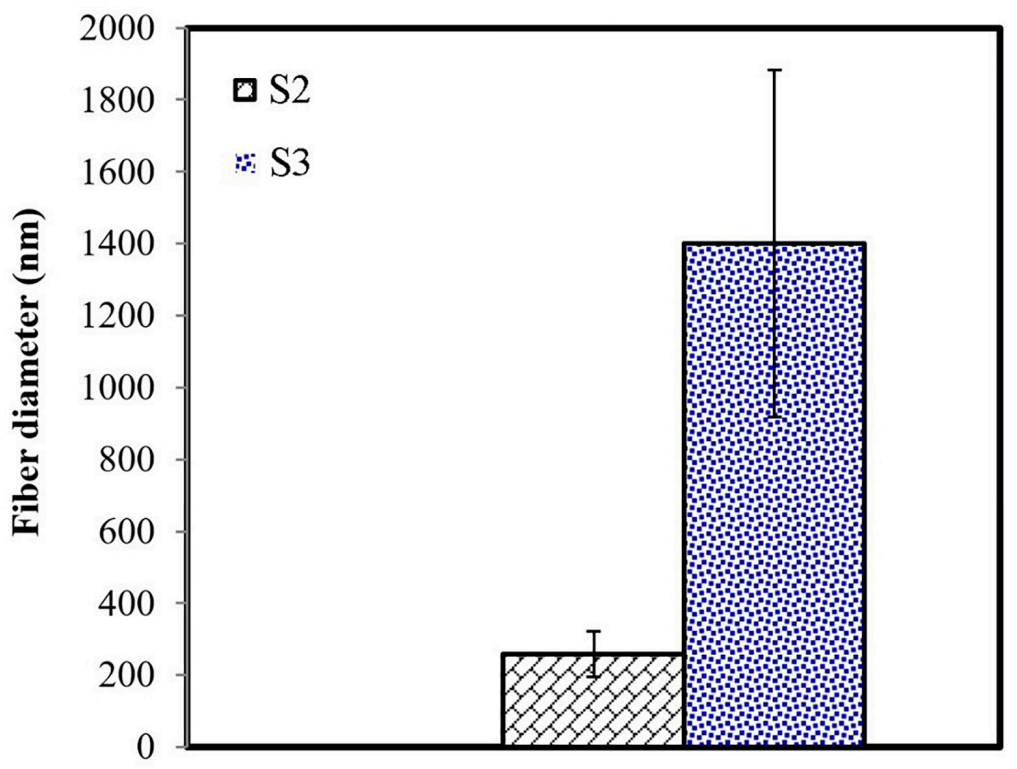

Figure 3. Average diameter of poly (acrylonitrile-co-methyl methacrylate) (PANMM) nanofibers (S2 and S3) and related standard deviation.

According to the results obtained from SEM images, the optimal concentration for electrospinning is $12 \%(w / v)$ of PANMM. At this concentration, smooth fibers with smaller diameters are formed. According to the studies performed on electrospinning of the PANMM solution, it can be said that under the conditions used in the electrospinning process, this polymer is electrospun well, and suitable fibers at optimal concentrations are produced.

By obtaining the appropriate concentration for the fabrication of PANMM nanofibers, the fabrication of PANMM nanofibers modified with BA was performed. As shown 
in Figure 1d, in PANMM nanofibers $+10 \%(w / w)$ of BA, the entry of boron into the polymer structure increases the diameter of the fibers by approximately $100 \mathrm{~nm}$ (Figure 2c), and almost smooth fibers, without any depressions on their surface, are produced. By increasing the concentration of boron in the nanofibers (Figure 1d,f), the fibers' average diameter increases from $375 \mathrm{~nm}$ (Figure 2c) in PANMM nanofibers $+10 \%$ of BA to $430 \mathrm{~nm}$ (Figure 2d) in PANMM nanofibers $+30 \%$ BA, and finally, to $618 \mathrm{~nm}$ (Figure 2e) in PANMM nanofibers $+50 \% \mathrm{BA}$. The trend of increasing the diameter of nanofibers with increasing the concentration of BA is clearly illustrated in Figure 4. The increase in the fibers' diameter is due to the increase in the viscosity of the solution, because by increasing viscosity, the rotations and bends of the electrospray projectile inside the electric field between two electrodes decrease, and the fiber diameter increases due to the reduction in the fibers' elongation [30]. In addition, it can be seen that the distribution of the fibers' diameter increases. The reason is that by increasing the concentration of BA in the electrospinning solution, the charge of the solution increases, and the electric field tension on the polymer projectile in some parts of the field becomes more than in other parts. Therefore, the average diameter of the fibers is smaller.

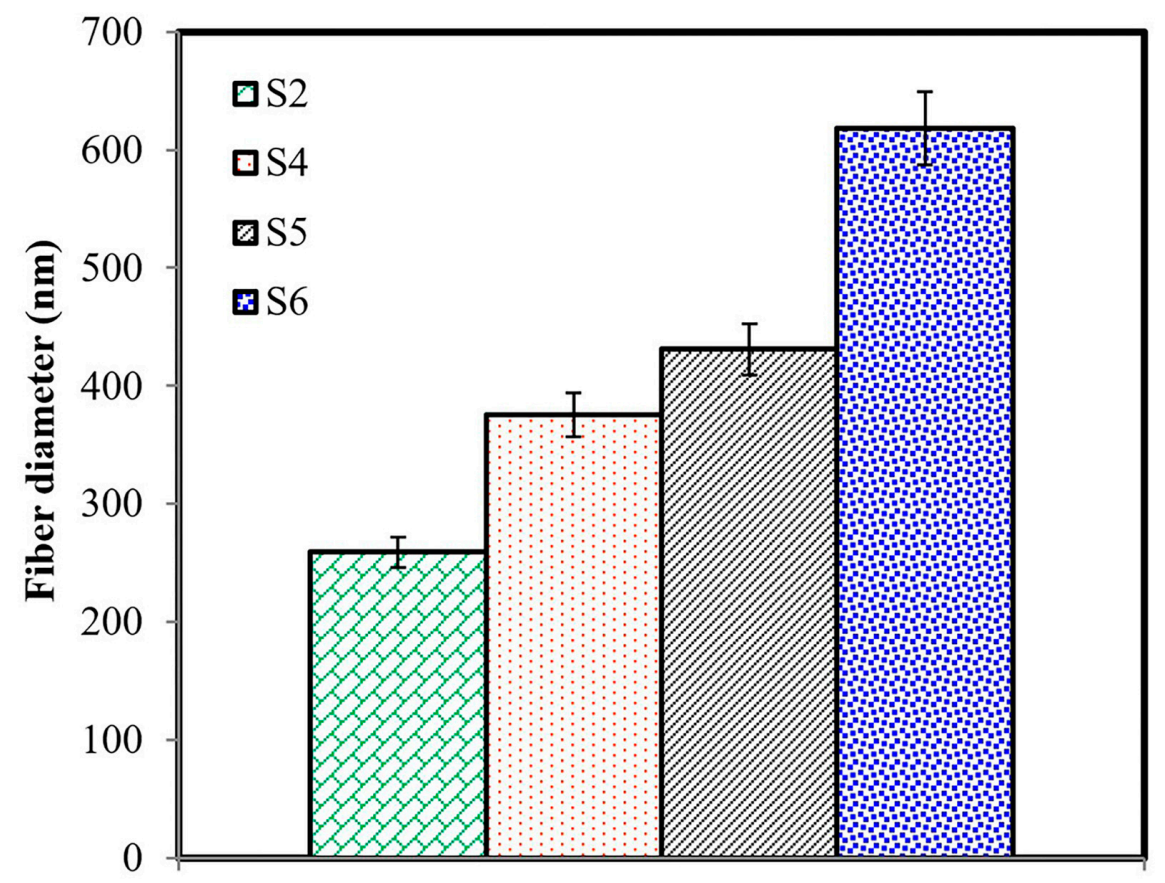

Figure 4. Average diameter of PANMM nanofibers (S2) and PANMM nanofibers + boric acid (BA) (S4, S5, and S6) and related standard deviations.

\subsection{Investigation of Chemical Structure of the Nanofibers}

In this study, FTIR spectroscopy was applied to detect different chemical groups in the structure of the nanofibers. First, the FTIR spectrum was recorded for pure BA powder and PANMM nanofibers. It can be seen from Figure 5 that the peak at $1190 \mathrm{~cm}^{-1}$ is related to the bending of the $\mathrm{BOH}$ group, and the relatively strong peak at $1450 \mathrm{~cm}^{-1}$ is also attributed to the bending vibration of the $\mathrm{B}-\mathrm{O}$ and $\mathrm{O}-\mathrm{H}$ groups. Another intense peak at the position of $3210 \mathrm{~cm}^{-1}$ can be related to the vibration of the $\mathrm{B}-\mathrm{O}$ and $\mathrm{O}-\mathrm{H}$ groups in the BA structure [31]. 


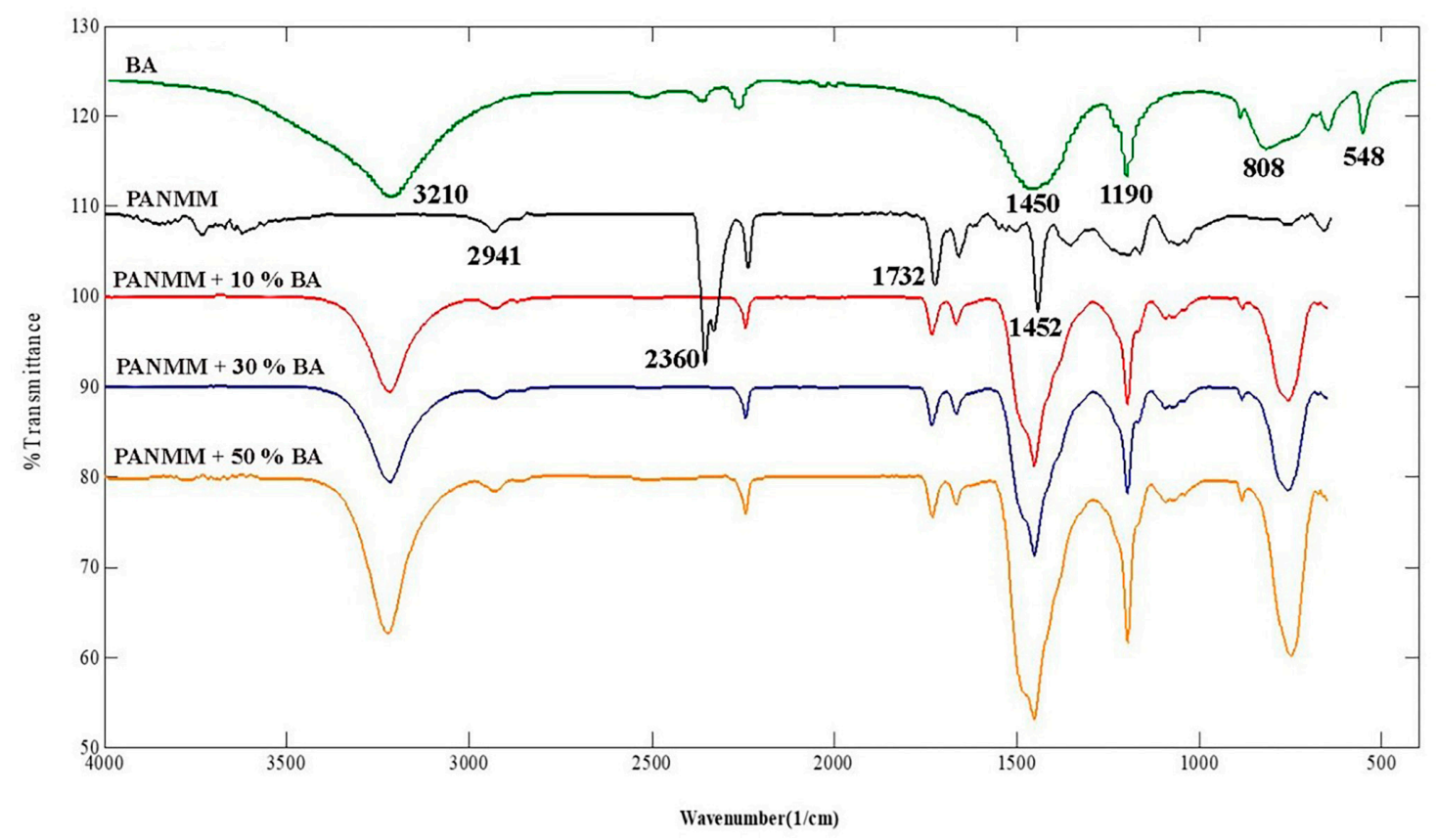

Figure 5. FTIR spectra of BA, PANMM, and PANMM + BA.

The FTIR spectrum of pure PANMM nanofibers is shown in Figure 5. It indicates the peaks at $2938 \mathrm{~cm}^{-1}$ (attributed to stretching in $\mathrm{CH}, \mathrm{CH}_{2}$, and $\mathrm{CH}_{3}$ groups), $2245 \mathrm{~cm}^{-1}$ (related to $\mathrm{C} \equiv \mathrm{N}$ stretching), $2361 \mathrm{~cm}^{-1}$ (related to the presence of $\mathrm{CO}_{2}$ ), $1732 \mathrm{~cm}^{-1}$ (related to the stretching of the carbonyl group $(\mathrm{C}=\mathrm{O})), 1452 \mathrm{~cm}^{-1}$ (related to bending $\mathrm{CH}_{2}$ ), and $1375 \mathrm{~cm}^{-1}$ (associated to bending CH) [32]. The peak in the range of $1000-1300 \mathrm{~cm}^{-1}$ is related to the ester group, which confirms that the polymer is a copolymer of acrylonitrile and methyl methacrylate.

The FTIR spectra of PANMM nanofibers with different percentages of BA were recorded and compared with the spectra of pure BA and PANMM. As shown in Figure 5, pure PANMM nanofibers do not show any peaks in the range of $3000-4000 \mathrm{~cm}^{-1}$, which indicates the absence of $\mathrm{O}-\mathrm{H}$ or $\mathrm{B}-\mathrm{O}$ groups in its structure. By increasing BA in the structure of PANMM nanofibers, the peak intensity related to $\mathrm{B}-\mathrm{O}$ and $\mathrm{C}-\mathrm{H}$ vibrations increases and a strong peak is observed at $3223 \mathrm{~cm}^{-1}$, which is related to the stretching vibrations of the O-H and B-O groups. There is a weak peak at $2930 \mathrm{~cm}^{-1}$ related to the stretching strength of $\mathrm{CH}, \mathrm{CH}_{2}$, and $\mathrm{CH}_{3}$ groups that can also be seen in pure PANMM nanofibers. The intensity of these peaks in BA-modified PANMM nanofibers is also very low. The peak recorded at $1452 \mathrm{~cm}^{-1}$ is attributed to the bending of $\mathrm{C}-\mathrm{H}$, which is overlapped with the peaks related to the bending of $\mathrm{B}-\mathrm{O}$ and $\mathrm{O}-\mathrm{H}$, and its intensity increases by increasing the percentage of BA in PANMM nanofibers [33]. It should be noted that the nitrile groups' cyclization is an intramolecular electron transfer reaction. A nucleophilic attack on the carbon atom of an adjacent nitrile group is made by the cyano $\mathrm{N}$ atom that carries a partial negative charge owing to the high polarity of the nitrile group, causing the $\mathrm{C} \equiv \mathrm{N}$ groups conversion to a conjugated $\mathrm{C}=\mathrm{N}$ structure [34]. A pair of electrons can be accepted by BA (as a typical Lewis acid). Thus, the electron-withdrawing ability of BA may cause the effect of retardation on the cyclization reaction and the prevention of the electron transfer among nitrile groups. It should be mentioned that BA has an inhibitory role in the cyclization reaction. Proceeding with the cyclization reaction during the stabilization leads to the gradual conversion of the $\mathrm{C} \equiv \mathrm{N}$ groups to $\mathrm{C}=\mathrm{N}$ groups [35]. The FTIR spectra show a decrease in the band intensity of the $C \equiv N$ groups. In the meantime, the band at $1445 \mathrm{~cm}^{-1}$ increases. According to the spectra, it is clear that in the modified nanofibers, increasing the concentration of BA does not cause the production of a new peak. Only one peak is removed, and the intensity of other peaks is increased owing to BA. These results are somewhat similar to the results in the spectra obtained from the electrospun nanofibers 
of organic and natural polymers. When there is no chemical reaction between the two components in the nanofiber structure, the functional groups of both components appear independently. In these cases, the component added to the substrate polymer is actually trapped between the polymer chains and appears separately in the existing nanofibers [36]. The same process is observed in cases where the nanocomposite is produced from a combination of nanoparticles and nanofibers. The nanoparticles that settle on the fibers have a spectrum corresponding to their functional groups and appear without interfering with the spectrum of the functional groups of the substrate polymer nanofibers. The results of FTIR studies show a slight reaction of BA with the substrate polymer.

\subsection{Investigation of the Thermal Properties of the Nanofibers}

TGA was used to study the effect of BA introduced to the nanofibers structure. Figure 6 shows the TGA curve of the pure and modified PANMM nanofibers. The pure nanofibers are decomposed in the temperature range of $312-484^{\circ} \mathrm{C}$, while the nanofibers containing BA are degraded between 298 and $470{ }^{\circ} \mathrm{C}$. These results show that the entry of BA into the PANMM nanofibers' structure reduces the thermal resistance of the nanofibers. The placement of BA molecules between the polymer chains increases the rate of degradation of the polymer, and thermal degradation begins at lower temperature [37,38]. It is also possible that the $\mathrm{O}$ - group of ionized $\mathrm{BA}$ also attacks the $\mathrm{C} \equiv \mathrm{N}$ group, converting it to the $\mathrm{C}-\mathrm{O}$ group. As can be seen in the FTIR spectra, the $\mathrm{C} \equiv \mathrm{N}$ peaks in pure PANMM nanofibers are partially eliminated, and the intensity of $\mathrm{C}-\mathrm{O}$ peaks is increased. The results of the TGA confirm the FTIR results.

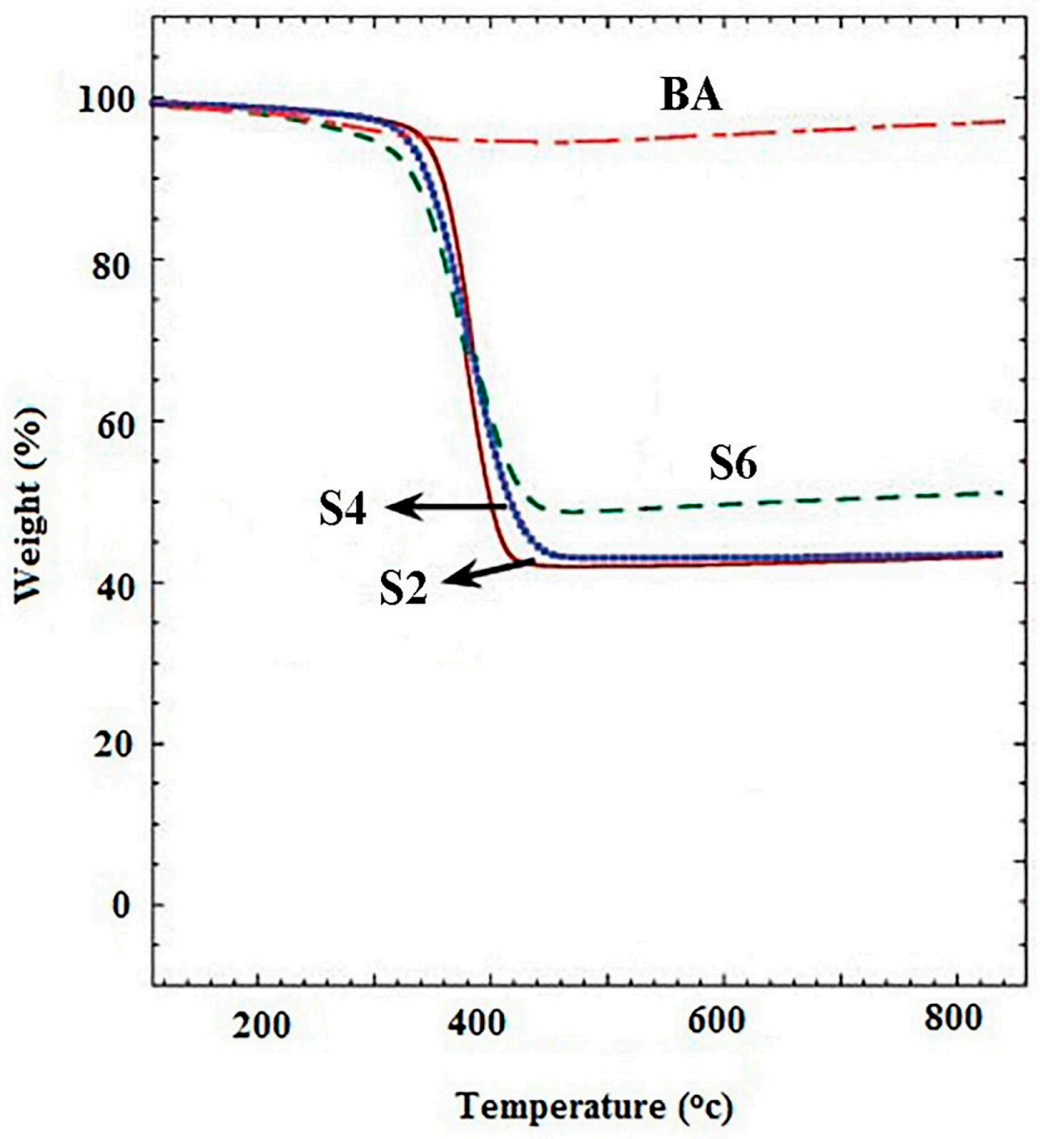

Figure 6. TGA results of BA, PANMM (S2), and PANMM + BA (S4 and S6).

\subsection{Investigation of the Structure of BA, PAN Nanofibers and PAN +BA}

As shown in Figure 7a, in the XRD pattern of BA powder, a very strong peak is observed at $2 \theta=15^{\circ}$, which is related to the tetragonal structure of BA. A peak with lower 
intensity is observed at $2 \theta=28^{\circ}$, which is related to the scattering of light from single BA plates. The XRD pattern of BA powder shows that this compound has a complete crystalline structure [39]. To study the crystal structure of PANMM nanofibers, its XRD pattern was investigated, and the result in Figure $7 \mathrm{~b}$ shows that PANMM nanofibers have a semi-crystalline or amorphous structure, and no strong peaks can be observed in the pattern. In the case of PANMM nanofibers containing BA (Figure 7c), the amorphous pattern of the polymer nanofibers is seen as compared with Figure $7 \mathrm{~b}$. The strongest peak of BA powder entirely vanished, and two new peaks were formed in the composite, suggesting a complete reaction or staying of some parts of BA in the amorphous phase, which could not be distinguished by the XRD analysis. It is reasonable to conclude that the oxidized PANMM nanofibers could also be crosslinked by BA. It can also be concluded that BA on the fiber surface has little influence on the free radical cyclization reactions of nitrile groups and obviously retards the stabilization process of PANMM.

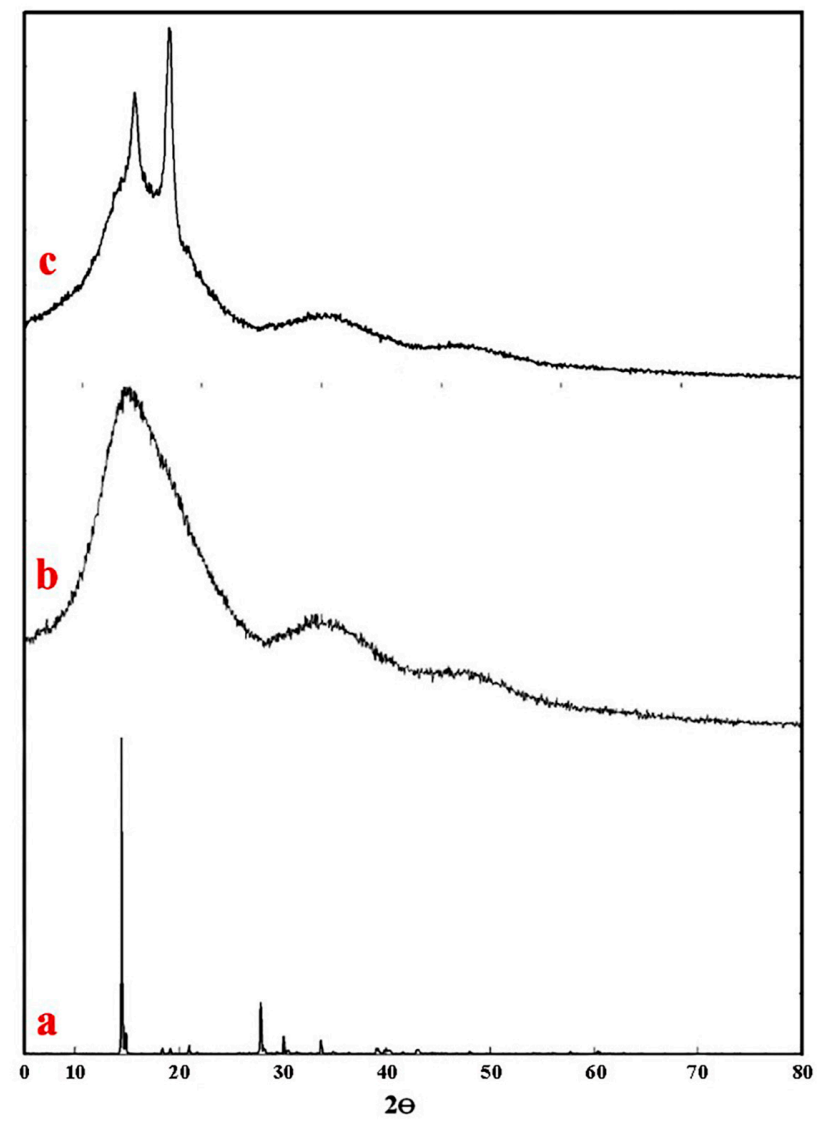

Figure 7. XRD patterns of (a) BA powder, (b) PANMM nanofibers, and (c) PANMM nanofibers + BA.

\subsection{Investigation of the Mechanical Strength of the Modified Nanofibers}

The mechanical behavior of polymers is expressed by examining the changes in stress to strain, and these changes can be shown in a diagram. Figure 8 shows a graph of the changes in the stress to strain of fibers before and after the introduction of BA. Table 2 shows the changes in mechanical strength of the nanofibers after modification and optimization with BA. Mechanical strength decreases after modification. The amount of this reduction is $14 \%$ in modulation and $6 \%$ in strength. In addition, the elongation and work of rupture increase to $4 \%$ and $10 \%$, respectively, which show a slight reduction in strength due to the reduction in the molecular weight of the polymer and the possible distance between the polymer chains, and also, a reduction in interactions between chains. An increase in length could be due to the sliding of the chains on top of each other [40]. The overall results show that the mechanical properties are maintained to an acceptable level. 


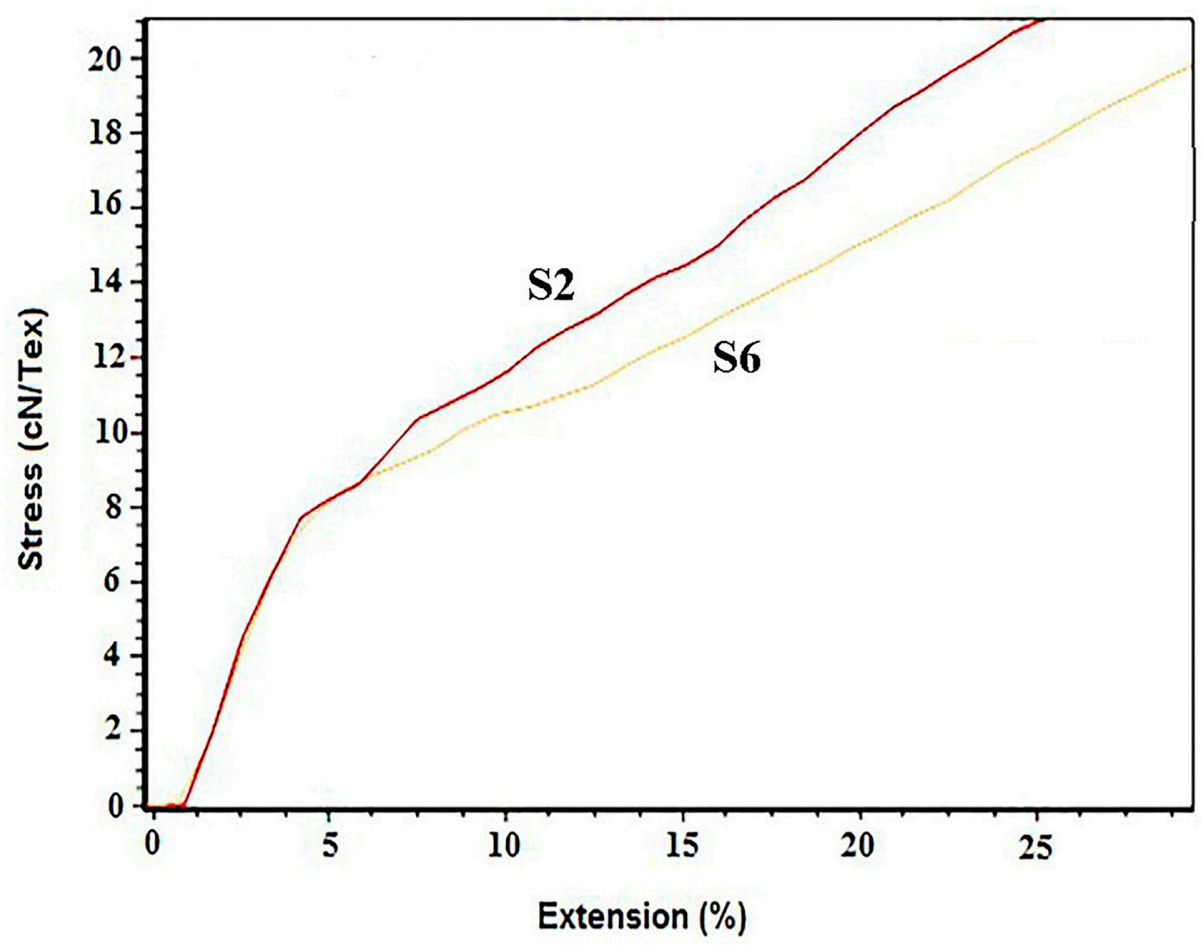

Figure 8. Stress changes of PANMM (S2) and PANMM nanofibers + BA (S6).

Table 2. Values of stress, strain, and elongation until rupture of unmodified and modified PANMM nanofibers.

\begin{tabular}{ccccc}
\hline Sample & $\begin{array}{c}\text { Work of Rupture } \\
\text { (gf/den) }\end{array}$ & Modulus (cN/tex) & Max Stress (cN/tex) & $\begin{array}{c}\text { Extension at Max Load } \\
\mathbf{( \% )}\end{array}$ \\
\hline PANMM & 3.179 & 309.1 & 21 & 25.31 \\
PANMM + BA & 3.547 & 255 & 19.76 & 29.3 \\
\hline
\end{tabular}

\section{Conclusions}

The purpose of this research was the fabrication of PANMM nanofibers containing ${ }^{10} \mathrm{~B}$. The study of the morphology of the nanofibers using SEM revealed that $12 \%(w / v)$ of PANMM is the optimal concentration for the electrospinning process, which could fabricate smooth and knotted fibers with an average diameter of $259 \pm 64 \mathrm{~nm}$. The XRD pattern of PANMM showed a semi-crystalline or amorphous structure of the nanofibers. The XRD pattern of the nanofibers containing BA showed that the strongest peak of BA powder entirely vanished, and two new peaks were formed in the composite, suggesting a complete reaction or staying of some parts of BA in the amorphous phase, which could not be distinguished by the XRD analysis. Mechanical properties decreased after the modification of PANMM. A 14\% reduction in modulation and a $6 \%$ reduction in strength were obtained. In addition, the elongation increased to $4 \%$, and the work of rupture increased to $10 \%$. According to the results obtained in this study, it can be said that PANMM nanofibers modified with BA can be a suitable choice for use in protective clothes of power plants and places where there is neutron pollution.

Author Contributions: Conceptualization, methodology, formal analysis, investigation, writingoriginal draft preparation: M.S., Z.M., P.S.K., H.J., M.F. Writing-review and editing: H.J. Supervision, project administration: M.S., H.J. All authors have read and agreed to the published version of the manuscript.

Funding: This research received no external funding.

Institutional Review Board Statement: Not applicable

Informed Consent Statement: Not applicable. 
Data Availability Statement: The authors declare that all data supporting this study's findings are available within the article.

Acknowledgments: The authors are thankful for the financial support received from Babol Noushirvani University of Technology.

Conflicts of Interest: The authors declared no potential conflicts of interest with respect to the research, authorship, and/or publication of this article.

\section{References}

1. Chand, S. Review carbon fibers for composites. J. Mater. Sci. 2000, 35, 1303-1313. [CrossRef]

2. Al-Enizi, A.M.; Zagho, M.M.; Elzatahry, A.A. Polymer-based electrospun nanofibers for biomedical applications. Nanomaterials 2018, 8, 259. [CrossRef]

3. Jadhav, S.A.; Dhavale, S.B.; Patil, A.H.; Patil, P.S. Brief overview of electrospun polyacrylonitrile carbon nanofibers: Prepara-tion process with applications and recent trends. Mater. Des. Process. Commun. 2019, 1, e83. [CrossRef]

4. Le, N.L.; Nunes, S.P. Materials and membrane technologies for water and energy sustainability. Sustain. Mater. Technol. 2016, 7, 1-28. [CrossRef]

5. Mirjalili, M.; Zohoori, S. Review for application of electrospinning and electrospun nanofibers technology in textile indus-try. J. Nanostructure Chem. 2016, 6, 207-213. [CrossRef]

6. Sahay, R.; Kumar, P.; Sridhar, R.; Jayaraman, S.; Venugopal, J.; Mhaisalkar, S. Electrospun composite nanofibers and their mul-tifaceted applications. J. Mater. Chem. 2012. [CrossRef]

7. Mustafov, S.D.; Mohanty, A.K.; Misra, M.; Seydibeyoğlu, M.Ö. Fabrication of conductive Lignin/PAN carbon nano-fibers with enhanced graphene for the modified electrodes. Carbon 2019, 147, 262-275. [CrossRef]

8. Tao, X.; Zhou, S.; Ma, J.; Xiang, Z.; Hou, R.; Wang, J.; Li, X. A facile method to prepare ZrC nanofibers by electrospinning and pyrolysis of polymeric precursors. Ceram. Int. 2017, 43, 3910-3914. [CrossRef]

9. Tao, X.; Zhou, S.; Xiang, Z.; Ma, J.; Hou, R.; Zhu, Y.; Wei, X. Fabrication of continuous ZrB2 nanofibers derived from boroncontaining polymeric precursors. J. Alloy. Compd. 2017, 697, 318-325. [CrossRef]

10. Nayak, R.; Padhye, R.; Arnold, L. Melt-Electrospinning of nanofibers. In Electrospun Nanofibers; Woodhead Publishing Series in Textiles; Woodhead Publishing: Cambridge, UK, 2017; pp. 11-40. [CrossRef]

11. Barhoum, A.; Pal, K.; Rahier, H.; Uludag, H.; Kim, I.S.; Bechelany, M. Nanofibers as new-generation materials: From spinning and nano-spinning fabrication techniques to emerging applications. Appl. Mater. Today 2019, 17, 1-35. [CrossRef]

12. Alcalá-Sánchez, D.; Tapia-Picazo, J.-C.; Bonilla-Petriciolet, A.; Luna-Bárcenas, G.; López-Romero, J.M.; Álvarez-Castillo, A. Analysis of Terpolymerization systems for the development of carbon fiber precursors of PAN. Int. J. Polym. Sci. 2020, $2020,1-13$. [CrossRef]

13. Mohamed, A.; Yousef, S.; Abdelnaby, M.A.; Osman, T.A.; Hamawandi, B.; Toprak, M.S.; Muhammed, M.; Uheida, A. Photocatalytic degradation of organic dyes and enhanced mechanical properties of PAN/CNTs composite nanofibers. Sep. Purif. Technol. 2017, 182, 219-223. [CrossRef]

14. Thenmozhi, S.; Dharmaraj, N.; Kadirvelu, K.; Kim, H.Y. Electrospun nanofibers: New generation materials for advanced ap-plications. Mater. Sci. Eng. B 2017, 217, 36-48. [CrossRef]

15. Nagarajan, S.; Belaid, H.; Pochat-Bohatier, C.; Teyssier, C.; Iatsunskyi, I.; Coy, E.; Balme, S.; Cornu, D.; Miele, P.; Kalkura, N.S.; et al. Design of boron nitride/gelatin electrospun nanofibers for bone tissue engineering. ACS Appl. Mater. Interfaces 2017, 9 , 33695-33706. [CrossRef]

16. Dadvar, S.; Tavanai, H.; Dadvar, H.; Morshed, M.; Ghodsi, F.E. UV-protection and photocatalytic properties of electrospun polyacrylonitrile nanofibrous mats coated with TiO2 nanofilm via sol-gel. J. Sol-Gel Sci. Technol. 2011, 59, 269-275. [CrossRef]

17. Cakmak, Y.; Canbolat, M.F.; Cakmak, E.; Dayik, M. Production and characterization of boron nitride-doped nanofiber mats created through electrospinning. J. Ind. Text. 2016, 47, 993-1005. [CrossRef]

18. Song, X.; Ma, Y.; Wang, J.; Liu, B.; Yao, S.; Cai, Q.; Liu, W. Homogeneous and flexible mullite nanofibers fabricated by electrospinning through diphasic mullite sol-gel route. J. Mater. Sci. 2018, 53, 14871-14883. [CrossRef]

19. Xue, J.; Wu, T.; Dai, Y.; Xia, Y. Electrospinning and electrospun nanofibers: Methods, materials, and applications. Chem. Rev. 2019, 119, 5298-5415. [CrossRef]

20. Shawgi, N.; Li, S.; Wang, S. A Novel method of synthesis of high purity nano plated boron carbide powder by a solid-state reaction of poly (vinyl alcohol) and boric acid. Ceram. Int. 2017, 43, 10554-10558. [CrossRef]

21. Mittal, G.; Rhee, K.Y.; Mišković-Stanković, V.; Hui, D. Reinforcements in multi-scale polymer composites: Processing, properties, and applications. Compos. Part B: Eng. 2018, 138, 122-139. [CrossRef]

22. Reid, R. Update on Boron Toxicity and Tolerance in Plants. In Advances in Plant Animal Boron Nutrition; Xu, F., Goldbach, H.E., Brown, P.H., Bell, R.W., Fujiwara, T., Hunt, C.D., Goldberg, S., Shi, L., Eds.; Springer: Dordrecht, The Netherlands, 2007; pp. 83-90.

23. Nable, R.O.; Bañuelos, G.S.; Paull, J.G. Boron toxicity. Plant Soil 1997, 193, 181-198. [CrossRef]

24. Liu, Y.; Kumar, S. Recent progress in fabrication, structure, and properties of carbon fibers. Polym. Rev. 2012, 52, 234-258. [CrossRef] 
25. Grassie, N.; Mcguchan, R. Pyrolysis of polyacrylonitrile and related polymers-IV. Thermal analysis of polyacrylonitrile in the presence of additives. Eur. Polym. J. 1971, 7, 1503-1514. [CrossRef]

26. Hwang, H.; Barakat, N.; Kanjwal, M.; Sheikh, F.; Kim, H.; Abadir, M. Boron nitride nanofibers by the electrospinning technique. Macromol. Res. 2010, 18, 551-557. [CrossRef]

27. Kim, S.H.; Kim, B.-H. Influence of boron content on the structure and capacitive properties of electrospun polyacryloni-trile/pitchbased carbon nanofiber composites. Synth. Met. 2018, 242, 1-7. [CrossRef]

28. Ju, A.Q.; Guang, S.Y.; Xu, H.Y. Effect of comonomer structure on the stabilization and spinnability of polyacrylonitrile co-polymers. Carbon 2013, 54, 323-335. [CrossRef]

29. Yan, X.; Zhou, W.L.; Zhao, X.S.; Xu, J.J.; Liu, P.Q. Preparation, flame retardancy and thermal degradation behaviors of polyacrylonitrile fibers modified with diethylenetriamine and zinc ions. J. Therm. Anal. Calorim. 2016, 124, 719-728. [CrossRef]

30. Andrei, R.D.; Marinoiu, A.; Marin, E.; Enache, S.; Carcadea, E. Carbon nanofibers production via the electrospinning process. Energies 2020, 13, 3029. [CrossRef]

31. Shimada, I.; Takahagi, T.; Fukuhara, M.; Morita, K.; Ishitani, A. FT-IR study of the stabilization reaction of polyacrylonitrile in the production of carbon fibers. J. Polym. Sci. Part A: Polym. Chem. 1986, 24, 1989-1995. [CrossRef]

32. Kim, D.; You, M.; Seol, J.H.; Ha, S.; Kim, Y.A. Enhanced thermal conductivity of individual polymeric nanofiber incorpo-rated with boron nitride nanotubes. J. Phys. Chem. C 2017, 121, 7025-7029. [CrossRef]

33. Zhao, J.; Zhang, J.; Zhou, T.; Liu, X.; Yuan, Q.; Zhang, A. New understanding on the reaction pathways of the polyacrylonitrile copolymer fiber pre-oxidation: Online tracking by two-dimensional correlation FTIR spectroscopy. RSC Adv. 2016, 6, 4397-4409. [CrossRef]

34. Wiles, K.B. Determination of Reactivity Ratios for Acrylonitrile/Methyl Acrylate Radical Copolymerization via Nonlinear Methodologies Using Real Time FTIR. Master's Thesis, Faculty of the Virginia Polytechnic Institute and State University, Blacksburg, VA, USA, 2002.

35. Coleman, M.M.; Sivy, G.T. Fourier transform IR studies of the degradation of polyacrylonitrile copolymers-I. Introduction and comparative rates of the degradation of three copolymers below $20{ }^{\circ} \mathrm{C}$ and under reduced pressure. Carbon 1981, 19, 123-126. [CrossRef]

36. Faraji, S.; Yardim, M.F.; Can, D.S.; Sarac, A.S. Characterization of polyacrylonitrile, poly (acrylonitrile-co-vinyl acetate), and poly (acrylonitrile-co-itaconic acid) based activated carbonnanofibers. J. Appl. Polym. Sci. 2017, 134, 1-10. [CrossRef]

37. Zhang, D.-L.; Zha, J.-W.; Li, W.-K.; Li, C.-Q.; Wang, S.-J.; Wen, Y.; Dang, Z.-M. Enhanced thermal conductivity and mechanical property through boron nitride hot string in polyvinylidene fluoride fibers by electrospinning. Compos. Sci. Technol. 2018, 156, 1-7. [CrossRef]

38. Haddadi, S.A.; Ramazani, A.S.; Talebi, S.; Fattahpour, S.; Hasany, M. Investigation of the effect of nanosilica on rheological, thermal, mechanical, structural, and piezoelectric properties of poly (vinylidene fluoride) nanofibers fabricated using an electrospinning technique. Ind. Eng. Chem. Res. 2017, 56, 12596-12607. [CrossRef]

39. Boland, C.S.; Barwich, S.; Khan, U.; Coleman, J.N. High stiffness nano-composite fibres from polyvinylalcohol filled with graphene and boron nitride. Carbon 2016, 99, 280-288. [CrossRef]

40. Wen, Y.; Lu, Y.G.; Qin, X.Y.; Xiao, H. Preparation of polyacrylonitrile high modulus carbon fibers by catalytic graphitization using boron. Mater. Sci. Forum 2011, 686, 778-783. [CrossRef] 